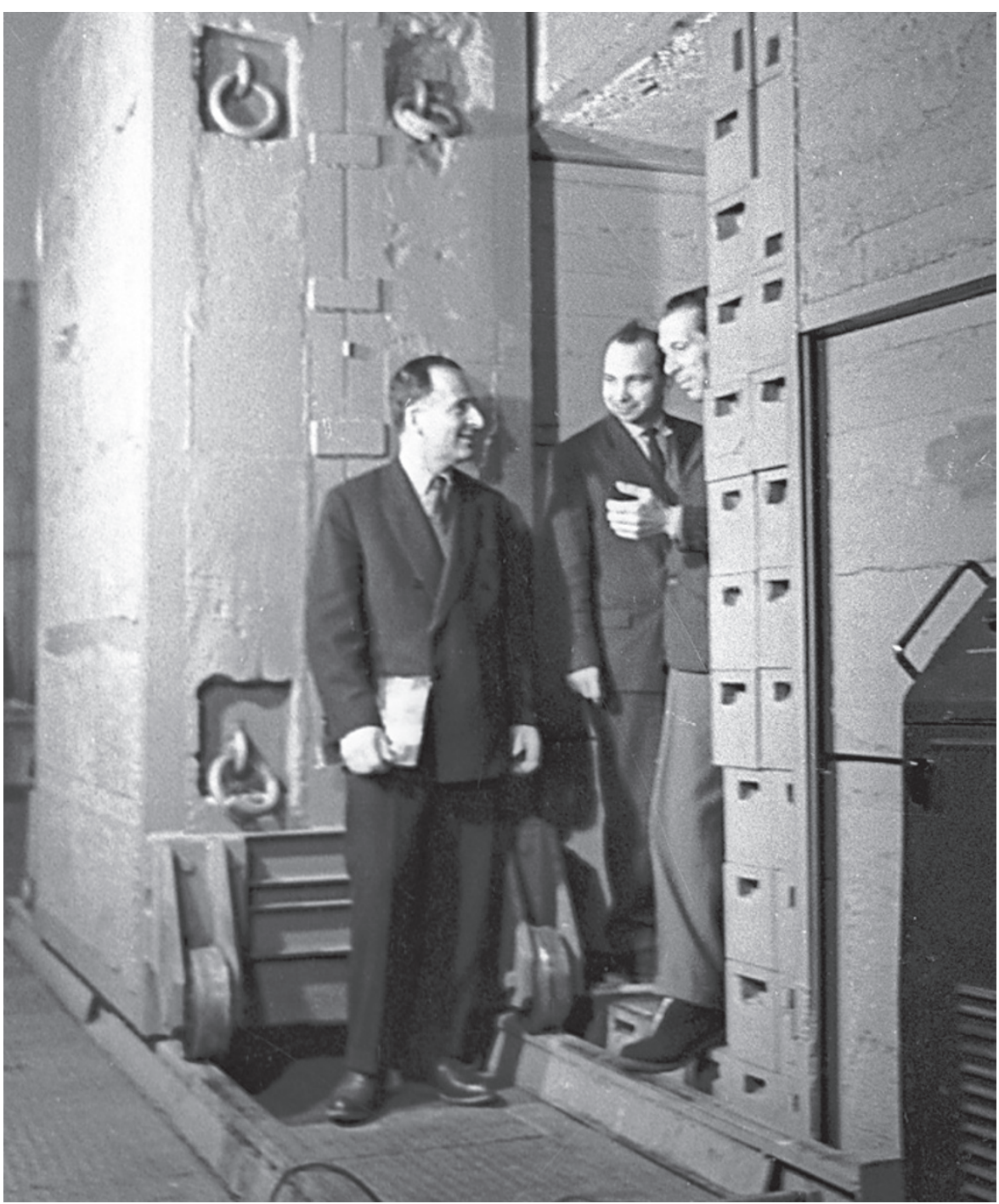

Physicist Bruno Pontecorvo (left) defected to the Soviet Union in 1950.

\section{New light on a cold war conundrum}

$\mathrm{W}$

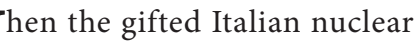
physicist Bruno Pontecorvo vanished with his family in the late summer of 1950, no one took any notice. It was more than two weeks before friends, family and, most importantly, the intelligence agencies of the United States and Britain - both countries where Pontecorvo had worked - realized that he had gone. And it was another five years before it was confirmed that Pontecorvo had defected to the Soviet Union.

The defection is one of the last great unsolved cold-war science mysteries. Did Pontecorvo, apparently on his way to winning a Nobel prize, flee because he was a devoted communist facing a hostile political climate? Or was he a spy running to his handlers? Physicist Frank Close believes that he has the answer. In Half-Life, Close explores what is now known as the Pontecorvo affair Woven into that chapter in the physicist's life are two love stories: his Swedish wife's love for him, and his love for communism. Neither ended well.

Born in 1913 into a successful Jewish family near Pisa, Pontecorvo pursued a career in physics, first as one of Enrico Fermi's "Via Panisperna" boys, and then leaving for Paris in 1936 to escape the rise of fascism and anti-Semitism. In France, he worked in the lab of Irène and Frédéric Joliot-Curie, and was swept up in the communist movement. Here he met and married his wife, Marianne Nordblom. As the war made its way to France, Pontecorvo and Marianne - now with a child - left for Tulsa, Oklahoma, where he used his expertise in looking at how neutrons interact with materials to create a new method for oil prospecting. But Pontecorvo's politics drew the attention of the FBI.

The federal investigators were not crack spy hunters. FBI agents visited Pontecorvo's Tulsa home in 1942 - when the United States was at war with Italy - and found communist literature in plain view. The couple's second son was named Tito, after the leader of communist Yugoslavia. Short of flying the hammer and sickle, it is hard to see how Pontecorvo could have been more open about his leanings. Yet the FBI merely wrote a report, which languished for several years. In the meantime, Pontecorvo moved to Canada to work on the Manhattan Project at the Chalk River Laboratories, and in 1949 left for the United Kingdom to work for the Atomic Energy Research Establishment at Harwell.

All seemed well until midway through the fateful summer holiday in 1950. The family, by then with three children, suddenly made a dash for Sweden, then Finland; here, Soviet agents secreted them across the border, with Pontecorvo hiding in the boot of a car. That marked the beginning of what Close calls the physicist's "half-life": the end of his Western career and the beginning of his life as Soviet scientist Bruno Maksimovich Pontecorvo.

Too many books are fêted as reading 'like spy novels', but Close's work deserves the accolade. He makes a good circumstantial case for Pontecorvo being a spy. Some of the

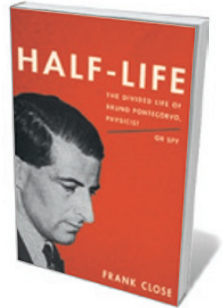

Half-Life: The Divided Life of Bruno Pontecorvo, Physicist or Spy FRANK CLOSE

Basic/Oneworld: 2015. evidence is relatively convincing, such as the assertion of a former KGB agent who claims that Pontecorvo did spy for the Soviets. On the weaker side, Close cites two pictures of Pontecorvo in Canada - standing with Chalk River scientists - looking away from the camera. Close suggests that Pontecorvo 
was already going to the US-Canadian border to rendezvous with a Soviet agent, and did not want his face recognized. Possibly; or perhaps he looked away by accident.

A bigger problem with this spy narrative is that it lacks a denouement - the dramatic unmasking of a double agent. Close implies that he has finally got the goods in an archival document: a letter from the British Embassy in Washington DC to the director-general of the UK intelligence agency MI5, dated 13 July 1950. It was this, Close writes, that would

"Too many books are fêted as reading 'like spy novels', but Close's work deserves the accolade." "lead me to solve the mystery of Bruno Pontecorvo's sudden disappearance". The letter is proof that FBI reports were finally making their way to Europe. Close argues that British double agent Kim Philby, who had access to it, tipped off Moscow; the Soviets then warned Pontecorvo that he was about to be exposed as a spy and arranged for his retreat.

Close's conclusion is in stark contrast to that of historian Simone Turchetti's The Pontecorvo Affair (University of Chicago Press, 2012). That book concluded that the Italian physicist was simply a committed communist, whose flight was triggered by a US patent lawsuit that he feared would lead to political persecution. Close's version is more plausible, but both lack definitive proof.

Close is at his best when describing Pontecorvo's work in neutrinos and neutron detection, demonstrating how groundbreaking it was, in spite of later attempts by Western governments to downplay his importance. But Close also occasionally takes liberties for the sake of drama. He describes an interrogation room painted in grey and "mustard", but his citation notes that he bases this scene on his knowledge of Soviet offices, not source materials. Almost nothing is known of Pontecorvo's dealings with the Soviet government. It is one thing to evoke colour, quite another to paint with the entire palette.

Half-Life reveals the real victim as Marianne, whose already shaky mental health deteriorated precipitously in the Soviet Union. Cut off from family and friends, she spiralled into depression and repeatedly entered psychiatric institutions, while Pontecorvo took on a mistress. Pontecorvo's love affair with communism did not end any better. He conceded in 1992, after the fall of the Soviet Union, that his dreams of a communist utopia were an illusion. "I was," he told a reporter, "a cretin."

Sharon Weinberger is a journalist specializing in national-security issues. She is currently writing a history of the US Defense Advanced Research Projects Agency. e-mail: sharonweinberger@gmail.com

\section{Books in brief}

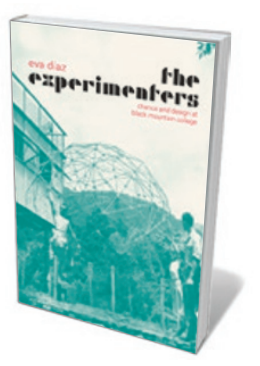

The Experimenters: Chance and Design at Black Mountain College Eva Díaz UNIVERSITY of CHICAGo PRESS (2015)

What links systems theorist and architect R. Buckminster Fuller with artistic innovators such as Josef Albers and John Cage? The answer is Black Mountain College, North Carolina. From 1933 to 1957, in this unaccredited institution in Appalachia, they and other "artistscientists" created an iconic lab for experimental research in the arts. As art historian Eva Díaz reveals in this engrossing study, their explorations in materials, form, chance and indeterminacy were never less than electrifying. Her sympathetic portrait of Fuller as a utopian saving the world through geodesic geometry is particularly assured.

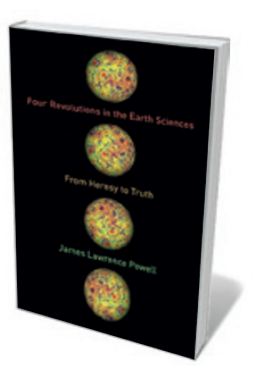

Four Revolutions in the Earth Sciences: From Heresy to Truth James Lawrence Powell COLUMBIA UNIVERSITY PRESS (2014) Deep time, continental drift, meteorite impact and climate change: each of these twentieth-century geoscientific discoveries was once viewed as heretical. So reminds geologist James Powell in this exemplary treatise on scientific progress. He traces the evolution of each landmark finding through the work of the dogged researchers who proved it, step by step. Many fights were hard-won, as shown in the efforts of Gene Shoemaker, Luis and Walter Alvarez, Robin Canup and others who established connections between meteorite impact, the birth of the Moon and the extinction of the dinosaurs.

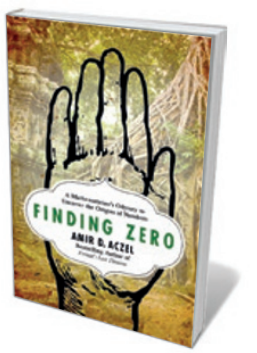

Finding Zero: A Mathematician's Odyssey to Uncover the Origins of Numbers

Amir D. Aczel Palgrave Macmillan (2015)

Mathematician Amir Aczel was obsessed from childhood with the origins of numerals. This bracing mathematical detective story reveals how he cracked the puzzle: by homing in on zero. Close readings of classical texts convinced him that this subtle concept emanated from the East. He treks through the findings of archaeological scholar George Cœdès, the surprising nexus of sex and mathematics, and much of southeast Asia before hitting pay dirt with a seventh-century artefact in a dusty Cambodian shed.

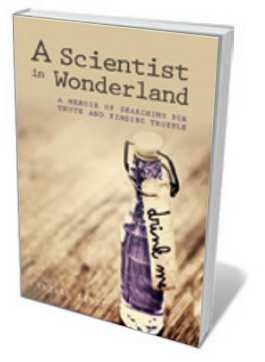

\section{A Scientist in Wonderland: A Memoir of Searching for Truth} and Finding Trouble

Edzard Ernst IMPRINT ACADEMIC (2015)

During his 1993-2011 tenure as the world's first chair in complementary medicine (at the University of Exeter, UK), Edzard Ernst scrutinized alternative medical treatments, turning up false claims and sparking a furore among enthusiasts. As he shows in this ferociously frank autobiography, his early career was as dramatic during a stint as chair of rehabilitation medicine at the University of Vienna, he uncovered the institution's historical involvement in medical experiments under the Third Reich. A clarion call for medical ethics.

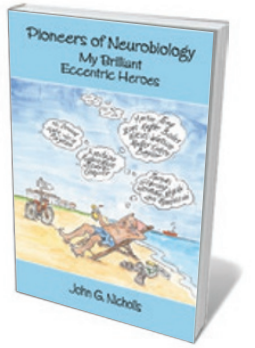

Pioneers of Neurobiology: My Brilliant Eccentric Heroes John G. Nicholls SINAUER ASSOCIATES (2015)

This scientific memoir by neurobiologist John Nicholls takes the form of short biographical sketches focusing on the eccentricities of key people he has worked with or encountered, from Nobel prizewinners to lab technicians. It is quite a list, including Stephen Kuffler, Bernard Katz, Rita Levi-Montalcini, Gunther Stent and James Watson. Nicholls's gently amusing anecdotes shed light on the developing environment of molecular neurobiology, mostly in Europe and the United States, since the 1950s. Barbara Kiser 